\title{
16 \\ A ORGANIZAÇÃO DA INSTRUÇÃo PÚBLICA E PARTICULAR NO MUNICÍPIO DE MONTE CARMELO, MG, EM 1892*
}

\author{
Aline Machado da Silveira \\ José Carlos Souza Araujo
}

A 15 de outubro de 1827 (BRASIL, 1827) foi instituída uma lei que ordenou a criação de escolas de primeiras letras em todas as cidades, vilas e lugares mais populosos. Conforme se abstrai do art. $6^{\circ}$ da referida lei, caberia aos professores ensinar a ler, escrever, aritmética, proporções, noções gerais e geometria, gramática da língua nacional e os princípios de moral cristã e da doutrina da religião católica e apostólica romana, além da leitura da Constituição do Império e História do Brasil.

Incumbia aos presidentes, assistidos pelos seus conselhos, enquanto os Conselhos Gerais não estivessem em exercício, e depois de haver recebido o aviso das Câmaras Municipais, determinar o número de escolas e localidades onde elas deveriam ser estabelecidas. Deviam igualmente fixar, a título provisório, os salários dos professores num limite de 200.000 a 500.000 mil réis por ano; a aprovação desta despesa cabia à Assembleia Geral Legislativa. (ALMEIDA, 1989, p. 60)

Nos termos do artigo 70 da Lei de $1^{\circ}$ de outubro de 1828 (BRASIL, 1828), caberia às câmaras municipais a

\begin{abstract}
“[...] inspecção sobre as escolas de primeiras letras, e educação, e destino dos orphãos pobres, em cujo numero entram os expostos; e quando estes estabelcimentos, e os de caridade, de que trata o art. 69, se achem por Lei, ou de facto encarregados em alguma cidade, ou vida a outras autoridades individuaes, ou collectivas, as Camaras auxiliarão sempre quanto estiver de sua parte para a prosperidade, e augmento dos sobreditos estabelecimentos".
\end{abstract}

Somente com o advento do Ato Adicional, por intermédio da Lei de 12 de agosto de 1834 (BRASIL, 1834), é que foram especificadas as relações entre Estado e educação, e delimitadas as competências das assembleias provinciais e do governo central. Pelo artigo 10, $₫ 2^{\circ}$, do Ato Adicional de 1834, foi conferido às províncias o direito de legislar sobre instrução pública e

${ }^{*}$ DOI - 10.29388/978-65-86678-49-9-0-f.267-284 
estabelecimentos próprios a promovê-la, excluindo-se, porém, de sua competência as Faculdades de Medicina e Direito e as Academias então existentes e outros quaisquer estabelecimentos que, no futuro, fossem criados por lei geral, o que provocou uma dualidade de sistemas entre o poder central e o provincial.

O resultado foi que o ensino, sobretudo o secundário, acabou ficando nas mãos da iniciativa privada, e o ensino primário foi relegado ao abandono, com pouquíssimas escolas, sobrevivendo à custa do sacrifício de alguns mestres-escolas, que, destituídos de habilitação para o exercício de qualquer profissão rendosa, se viam na contingência de ensinar (ROMANELLI, 2005).

$\mathrm{Na}$ província mineira, o primeiro ato de regulamentação do ensino primário após a Independência foi a Lei $\mathrm{n}^{\circ}$ 13, de 28 de março de 1835 (MINAS GERAIS, 1835), que dividiu a Província em 15 círculos literários, chefiados dos delegados do governo, constituindo uma necessária descentralização do ensino, medida eficiente em uma província tão vasta e tão escassa de meio de transporte.

Naquele tempo, havia escolas primárias de $1^{\circ}$ e $2^{\circ}$ gráus, ficando estas nas povoações mais importantes e com o currículo mais amplo.

Havia multas para os responsáveis pelos alunos quando êstes não eram assíduos às aulas. De acôrdo com o artigo $9^{\circ}$ da Lei $n^{\circ} 13$ acima citada, os professores das escolas particulares deveriam estar devidamente habilitados para exercer o magistério. (MOURÃO, 1959, p. 389-390)

Posteriormente, em 1848 (MINAS GERAIS), houve uma centralização do ensino, com a criação de um órgão superintendendo todos os círculos literários. Estabeleceu-se, assim, a Diretoria Geral de Instrução Pública, por intermédio da Lei $\mathrm{n}^{\circ}$ 435, de 19 de outubro de 1848, órgão opinativo sobre o ensino, com atribuição de receber propostas e reclamações dos professores.

Pela Lei no 1064, de 4 de outubro de 1860 (MINAS GERAIS, 1860), revoga-se o regulamento n. ${ }^{\circ} 44$, suprime a agência geral de instrução pública, e autoriza a presidência a expedir novo regulamento. Assim sendo, houve uma reforma da organização do ensino público, e passou a estabelecer regras sobre a instrução particular em colégios e escolas. Posteriormente houve “[...] o Regulamento $\mathrm{n}^{\circ} 49$, a Lei mineira $\mathrm{n}^{\circ} 1.618$, de 2 de novembro de 1869, que estabeleceu o ensino particular primário ou secundário em qualquer lugar da Província, dispensada a licença bem como a prova de capacidade dos professores" (MOURÃO, 1959, p. 396). 
Em meio a duras críticas em relação à ordem imperial vigente, de heranças do período colonial e escravocrata, foram envidados esforços para instituir reformas no intuito de civilizar a sociedade e fomentar a modernidade e o progresso, visando formar pessoas. Assim, emergiram árduos debates acerca dos altos índices do analfabetismo ${ }^{1}$ e dos novos métodos de alfabetização, que gradativamente transformariam aquele cenário.

O processo de transição do Império para a República foi marcado pela proliferação de uma grande massa de analfabetos, o que se deveu principalmente a fatores como baixos salários dos professores, que impedia, sobremaneira, a contratação de pessoal mais qualificado, e devido ao fato de a educação ser encarada como um privilégio concedido pelo Estado, e não um direito dos súditos do Imperador.

A esta causa primordial de insucesso, deve-se ajuntar o afastamento natural das pessoas inteligentes, de uma função mal remunerada e que não encontra na opinião pública a consideração a que tem direito muito mais que as outras, porque o professor, o institutor e a institutora substituem, em certa medida, o pai e a mãe de família, inaptos para cumprir completamente seu dever social. (ALMEIDA, 1989, p. 65)

Nas palavras de Nagle (1974, p. 282-283), em termos práticos, de pouco valeu a passagem do Império para a República, que são consideradas duas formas doutrinariamente diversas de organização do Estado, além de pouco valerem as pregações dos propagandistas e idealizadores da República acerca da instrução, uma vez que permaneceram os mesmos princípios do regime anterior, notadamente o descaso com a educação popular, que foi o aclamado instrumento do novo regime.

Não obstante a libertação das antigas províncias em relação ao poder central, o mesmo não ocorreu com as atribuições no domínio da escolarização. O novo regime, conhecido por Primeira República, apegou-se à centralização cultural, mantendo a escola secundária e superior dentro de sua exclusiva esfera jurisdicional, embora tenha dividido a responsabilidade pela educação básica entre a União e os governos estaduais.

\footnotetext{
${ }^{1}$ Em 1872 a taxa de analfabetismo para o conjunto do país era de 82,3\% para as pessoas de 5 anos ou mais, situação esta que se mantém inalterada pelo menos até o segundo censo, realizado em 1890 (82,6\%), já no início da República. O analfabetismo, portanto, emergiu no Brasil como uma questão política, não como uma questão econômica. É no período 1890 a 1920 que tem início a tendência secular de queda do analfabetismo no Brasil (FERRARO, 1985).
} 
Pelo artigo $2^{\circ}$, do Decreto $\mathrm{n}^{\circ} 7$, de 20 de novembro de 1889 (BRASIL, 1889), a instrução pública foi entregue aos governos estaduais, podendo tal prerrogativa ser suprimida ou ampliada pela União. Com a instalação do regime republicano, fica dentre as atribuições dos Estados federados a competência sobre os assuntos de instrução pública (NAGLE, 1974).

Sob o prisma da descentralização, típica dos sistemas federativos, foi promulgada aos 15 dias de junho de 1891 a Constituição de Minas Gerais. Assim, "[...] cabe explicitar, sobretudo, qual é o significado que esta Constituição atribuiu à instrução pública, às câmaras municipais e aos orçamentos municipais.” (BORGES; ARAUJO, 2015, p. 386).

Conforme expõe seu artigo $3^{\circ}, \int 6^{\circ}$ (MINAS GERAIS, 1891) “[...] o ensino primário será gratuito e o particular exercido livremente", ficando dentre as competências do Congresso "[...] legislar sobre o ensino secundário e superior, que será livre em todos os gráus" (art. $5^{\circ}$ ). Ainda no mesmo dispositivo, no artigo 75, foi prescrito que uma lei especial deveria regular a organização dos municípios, atribuindo às Câmaras Municipais a organização de questões relativas ao orçamento, criação de empregos, desapropriação, instrução pública etc. (MINAS GERAIS, 1891).

Ficou estabelecido pelo artigo 117, que "[...] a lei de organisação de instrução pública estabelecerá":

\footnotetext{
$1^{\circ}$ A obrigatoriedade do aprendizado em condições convenientes;

$2^{\circ}$ Preferencia dos diplomados pelas escolas normaes, para a investidura no magistério;

$3^{\circ}$ Instituição do fundo escolar;

$4^{\circ}$ Fiscalisação do Estado, quanto a estabelecimentos particulares de ensino, somente no que diz respeito à higyene, moralidade e estatística. (MINAS GERAIS, 1891, s.p.)
}

Assim, em atendimento ao mandamento constitucional e a fim de possibilitar um maior protagonismo dos municípios, foi instituída aos 14 dias do mês de setembro de 1891, a Lei no 2 (MINAS GERAIS, 1891), dispondo sobre a organização municipal, reservando às câmaras ampla liberdade de ação nas tratativas dos assuntos de interesse local:

Contudo, evidentemente que o novo estado de Minas Gerais, embora de considerável importância, não poderia ditar normas de ensino, reformando as do regime decaído, antes que a situação se normalizasse e que houvesse diretrizes de âmbito federal. Estas vieram da ilusória e infecunda orientação positivista de Benjamim Constant que, como primeiro Ministro da Instrução, elaborou o decreto 981, de 8 de novembro de 1890, regulando o ensino primário e secundário, criando o Conselho da Instrução Superior. Tal Decreto 
recebeu duras críticas por ser considerado fora da realidade brasileira (MOURÃO, 1962).

Somente três anos após a proclamação da República é que surgiu uma lei com a finalidade de reformar a instrução pública em Minas Gerais, em seus diferentes graus. Esta foi a Lei $\mathrm{n}^{\circ}$ 41, de 3 de agosto de 1892 (MINAS GERAIS, 1892), chamada de reforma Afonso Pena:

A reforma foi essencialmente descentralizadora. Criou um órgão técnico para estudar métodos e processos de ensino. Estabeleceu a inspetoria ambulante para permitir a fiscalização das escolas do interior. Os inspetores ambulantes opinavam tecnicamente sobre as escolas públicas e sôbre as particulares, subvencionadas ou em condições de sê-lo. (MOURÃO, 1962, p. 19-20)

Os Conselhos escolares municipais tiveram a possibilidade de atribuir à municipalidade a fiscalização da escola, o que apresentava maior eficiência pela ação permanente desses conselhos. Possibilitou-se, assim, uma útil descentralização do ensino. As "[...] atribuições dos diretores e vice-diretores das escolas normais põem ainda mais em evidência a liberdade de ação, independentemente do órgão central" (MOURÃO, 1962, p. 20).

Fato é que essa aproximação da gestão do ensino com a população muito contribuiu para o melhoramento da realidade educacional. Surgem, assim, as primeiras intenções e iniciativas de organização da instrução pública no município de Monte Carmelo, visando dar efetividade aos mandamentos constitucionais e à lei de organização.

\section{Origem e formação de Monte Carmelo, MG no Século XIX}

Monte Carmelo, também conhecida por Capital da Telha, devido ao seu solo rico em argila, que manteve por muito tempo sua principal atividade econômica, a ceramista, está localizada na região Oeste de Minas Gerais, na Zona Alto Paranaíba, com uma população atualmente estimada em aproximadamente 48 mil habitantes, segundo dados do Instituto Brasileiro de Geografia e Estatística - IBGE apurados em 2017. Atualmente o município abrange os distritos de Celso Bueno e Gonçalves. 
Figura 1 - Mapa do Estado de Minas Gerais, com destaque para o Município de Monte Carmelo.

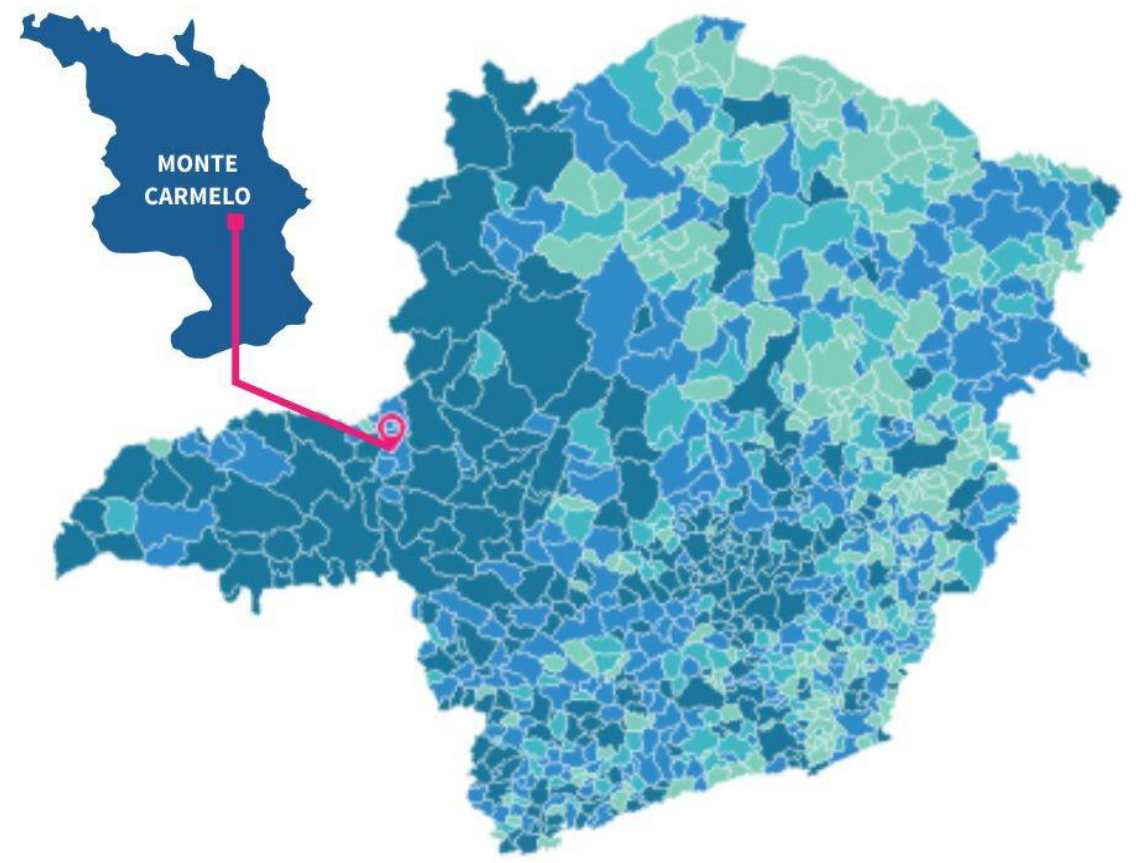

Fonte: Disponível em: http://www.montecarmelo.mg.gov.br/perfil. Acesso em: 28 de out. de 2019, s.p.

O município possui uma área física de $2.494 \mathrm{KM}^{2}$, a sede municipal, situada a $869 \mathrm{~m}$ de altitude, tem como coordenadas geográficas $18^{\circ} 43^{\prime} 36^{\prime \prime}$ de Latitude Sul e $47^{\circ} 29^{\prime} 42^{\prime \prime}$ de Longitude W Gr., distante da Capital do estado, em linha reta, $399 \mathrm{KM}$, tendo como atividade predominante a agricultura, pecuária e silvicultura (IBGE, 1959).

Segundo dados do recenseamento de 1890, disponível no anuário estatístico de Minas Gerais, naquele ano o então município contava com uma população de 13.711 habitantes, compreendendo o distrito de Água Suja, atual Romaria, MG. A título comparativo, conforme o recenseamento de 1920, Monte Carmelo possuía 24.768 habitantes, dos quais 18.067 pertenciam ao município-sede 18.067; os três distritos dos municípios em apreço perfaziam 6.701 (ARAUJO, 2012).

De acordo com o professor Yermak Slywitch (1995), datam de 1840 os primeiros movimentos que deram origem ao povoado de Carmo da Bagagem, quando diversas famílias vindas de São João Del Rei e Tamanduá (atual 
Itapecerica), além de outras localidades, foram atraídas pelos garimpos de diamantes em Bagagem (atual Estrela do Sul), e depois em Nossa Senhora D’Abadia de Água Suja, atual Romaria. “O fascínio despertado pelos garimpos fartos de diamantes, além do clima saudável das montanhas, contribuíram para a fixação destas famílias na região" (SLYWITCH, 1995, p. 5).

Aduz Matos que

O fluxo migratório rumo a Bagagem encontraria pela frente grandes dificuldades, uma vez que o local não oferecia condições básicas para abrigar as famílias. A alternativa era seguir em direção ao território que hoje é Monte Carmelo, localizado numa planície de clima ameno, água cristalina, terra avermelhada e de vastos cerrados. (MATOS, 2013, p. 25)

E foi devido a esses fatores: a precariedade, desorganização e má índole dos moradores da região garimpeira, que os bandeirantes queriam encontrar um lugar pouco afastado de Bagagem para trazer suas famílias, quando, observadas a boa quantidade e qualidade da água desta localidade, especialmente nos córregos Mumbuca e Olaria, dentre outros fatores, por aqui decidiram se instalar.

O primitivo povoado chamou-se Arraial do Carmo da Bagagem, em consequência das primeiras construções erguidas terem sido em um terreno doado pela fazendeira Clara Chaves à Nossa Senhora do Carmo, na extensão de uma légua quadrada $(6 \mathrm{~km} \times 6 \mathrm{~km})$, para que construíssem uma capela em louvor à Santa (SLYWITCH, 1995).

De acordo com fontes disponíveis no site do município, em 1859, o Arraial do Carmo da Bagagem foi desmembrado do território de Patrocínio e anexado à freguesia de Bagagem, atual município de Estrela do Sul, que se encarregou de todas as decisões e da administração daquele povoado, sendo que em 14 de setembro de 1870 emancipou-se eclesiasticamente da jurisdição de Bagagem, tornando-se paróquia e distrito. A paróquia foi erguida em 1870, e o distrito recebeu a denominação de arraial ou povoado de Carmo da Bagagem, tendo Nossa Senhora do Carmo como padroeira da cidade, cuja Ordem teve origem em Israel.

Aos 6 dias do mês de outubro de 1882, pela Lei provincial $n^{\circ} 2.927$, o povoado foi elevado à categoria de Vila, denominada por Nossa Senhora do Carmo da Bagagem. Pela Lei estadual no 23, de 24 de maio de 1892 (MINAS GERAIS, 1892), ficou estabelecido que todas as vilas-sedes de comarcas ficariam elevadas à categoria de cidade.

Por 38 anos, a partir da referida data, a Câmara de Vereadores foi constituída por cidadãos que se autoescolhiam como intendentes, mediante aprovação automática dos coronéis e pelas personalidades mais influentes. "O presidente da câmara era o intendente, cargo equivalente ao de prefeito. No 
período de 38 anos, apenas cinco cidadãos, em revezamento, ocuparam o cargo" (PORTILHO, 2013, p. 57).

Assim, o antigo povoado de Nossa Senhora do Carmo da Bagagem passa a denominar-se tão somente Carmo da Bagagem. Sendo que aos 25 dias de junho de 1900, a Lei estadual no 286 (MINAS GERAIS, 1900), de iniciativa do então Presidente do Estado, o Senhor Francisco Silviano de Almeida Brandão, determinou a mudança do nome da cidade, município e comarca do Carmo da Bagagem para cidade, município e comarca de Monte Carmelo.

O então município de Monte Carmelo passa a abranger quatro distritos: Monte Carmelo, sede, Água Suja (atual Romaria), Iraí e São Sebastião da Ponte Nova, sendo posteriormente, pela Lei estadual $n^{\circ} 843$, de 07 de setembro de 1923, que dispôs sobre a divisão administrativa do estado, criado e também anexado ao município o distrito de Doradoquara (atual Douradoquara), conforme previsão do seu artigo $5^{\circ}$, inciso XXVI (MINAS GERAIS, 1923).

Conforme assevera Slywitch (1995), Monte Carmelo é o nome de uma montanha, rica em cavernas e coberta de exuberante vegetação, no litoral de Israel, nas proximidades da cidade de Haifa, onde já se abrigaram inúmeros Ascetas Hebraicos, como Elias e Eliseu. Carmelo em Hebraico, língua oficial em Israel, é Carm/el, que significa "Uvas de Deus".

A cidade foi batizada com o referido nome quando uma comitiva de carmelitas chegou na região e identificou um morro, hoje conhecido como igrejinha, semelhante ao da antiga Palestina, perto de Nazareth, existente no litoral de Israel, nas proximidades da cidade de Haifa, onde se encontra a sede da Congregação das Carmelitas. Sendo assim, o nome foi adotado em consideração à ordem de Nossa Senhora do Carmo e ao monte existente nas proximidades da cidade (SLYWITCH, 1995).

Figura 3 - Capela São José - Igrejinha

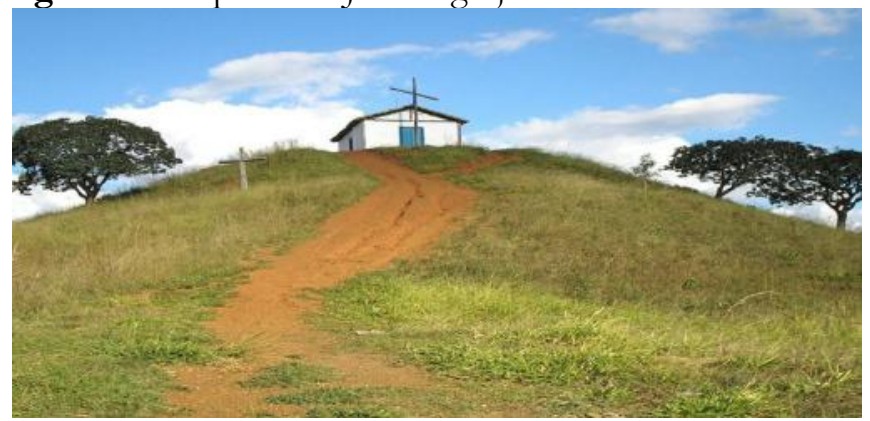

Fonte: Disponível em:

https://www.expressodocerrado.com.br/2017/03/20/capela-desao- jose/. Acesso em: 20 mar. 2019. 
A comarca foi instituída pela Lei estadual $\mathrm{n}^{\circ} 11$, de 13 de novembro de 1891 (MINAS GERAIS, 1891) com a denominação de Carmo da Bagagem; a instalação solene deu-se em 15 de abril de 1892, tendo como primeiro Juiz de Direito, o Dr. Tito Fulgêncio Alves Pereira, que veio a ser um dos nomes de maior projeção na magistratura mineira, com atuação entre 1893 e 1896 nesta comarca, sucedido pelo Juiz de Direito, Dr. José Amorim Salgado (IBGE, 1959).

No mesmo ano:

O poder executivo é organizado, sendo nomeado primeiro prefeito José Cândido Rocha, com mandato entre 07 de março de 1892 e 24 de janeiro de 1894.

A administração Cândido Rocha encontrou um município em condições incipientes, com um comércio à base do escambo, transporte através de carro de boi e lombo de animais, enormes distâncias de outras cidades. Uberaba era o principal centro onde os carmelitanos efetuavam negócios. O que mais se evidenciava, porém, era uma economia de subsistência onde o que se produzia no município era ali mesmo consumido. (MATOS, 2013, p. 27)

Monte Carmelo, a exemplo das outras cidades do interior brasileiro, inserida no processo que culminou com a adoção da República, passa a ser gerida pelos coronéis oriundos das oligarquias locais. Surgiram vários personagens portadores de patentes (MATOS, 2013, p. 27-28). A instalação da comarca ocorreu no mês seguinte ao da reabertura das Câmaras Municipais no estado de Minas Gerais:

Pelo artigo $8^{\circ}$ da Constituição mineira de 1891, cabia privativamente ao Congresso legislar sobre câmaras municipais, e nos termos do artigo 75, destinado às tratativas relativas aos municípios, "uma lei especial regulará a organização dos municípios, respeitadas as bases seguintes":

I A população e cada municipio, que for creado, não será inferior a vinte mil habitantes.

II A administração municipal inteiramente livre e independente em tudo quanto respeita ao seu peculiar interesse, será exercida em cada município por um conselho eleito pelo povo, com a denominação de Camara Municipal.

III $\mathrm{O}$ numero de vereadores de villas e cidades não será inferior a 7 nem superior a 15.

IV $\mathrm{O}$ orçamento municipal, que será annuo e votado em época prefixada, a policia local, a divisão districtal, a creação de empregos municipaes, a instrucção primaria e profissional, a desapropriação por necessidade ou utilidade do municipio e alienação de seus bens, nos 
casos e pela forma determinada em lei, são objecto de livre deliberação das camaras municipaes, sem dependencia de approvação de qualquer outro poder, guardadas as restricções feitas nesta Constituição. [...]. (MINAS GERAIS, 1891).

Desde então começaram os primeiros debates acerca da instituição do Regulamento da Instrução Pública e privada no município, sob a presidência do então prefeito e presidente da Câmara, o Sr. José Cândido Rocha e demais vereadores: Alexandre Veiga, José de Novaes Freitas, Zacarias Borges Tavares, Joaquim Pinto de Oliveira e José Fernandes Mundim.

Em atendimento ao prescrito na Constituição mineira e na Lei estadual $\mathrm{n}^{\circ}$ 02, fica estabelecido, pela Lei $\mathrm{n}^{\circ}$ 05, de 6 de novembro de 1892 o Regulamento da Instrução Pública e Particular do município, a ser analisado em seguida.

\section{O regulamento da instrução pública e particular de Monte Carmelo, MG, em 1892, na expressão republicana}

Não obstante a legislação estadual vigente nesse sentido, o art. $1^{\circ}$ do regulamento dispôs sobre a obrigatoriedade da instrução primária no município, para todos os menores de 7 a 14 anos do sexo masculino, e de 7 a 11 anos do sexo feminino, residentes dentro da área de seis quilômetros onde houvesse escola pública estadual, municipal ou particular subvencionada, desde que esses menores não dispusessem de impossibilidade física ou moral, sendo esses os únicos motivos aceitáveis para o abandono escolar no período delimitado, salvo se o aluno fosse julgado habilitado em exame.

A idade dos menores deveria ser verificada pelas declarações dos pais, tutores ou patronos, ou, na falta destes, dos párocos e demais obrigados a prestar os encargos do registro civil, os quais ficariam sujeitos à obrigação e penas da lei no caso de recusa ou inexatidão das informações. Não se admitia matrículas de menores de 06 (seis) anos, maiores de 14 (quatorze) anos, e nem de menores que sofressem de moléstia contagiosa. $\mathrm{Na}$ falta de informações ou impossibilidade de se obter a idade, esta seria calculada pelos sinais exteriores e desenvolvimento psíquico dos menores.

Nos termos do art. $9^{\circ}$ e $10^{\circ}$, a instrução pública poderia ser ministrada em aulas públicas ou particulares, subvencionadas ou não, ficando o professor particular que ensinasse na própria casa, na dos pais, tutores ou patronos, obrigado a enviar trimestralmente aos Conselhos de Instrução minuciosa informação do ensino durante o trimestre anterior, de forma que fosse permitido o reconhecimento do grau de adiantamento dos seus alunos. 
Pelo art. $13^{\circ}$, deveria haver na cidade e em cada distrito do município um conselho composto do Presidente do Conselho Distrital, de um cidadão nomeado pela Câmara Municipal e outro nomeado pelo presidente do Conselho Distrital, o qual seria denominado por Conselho de Instrução Pública, com as incumbências a seguir.

Quanto à organização, o regulamento dispôs que o conselho deveria:

$\int 1^{\circ}$ Organisar dentro do primeiro mez de seu exercicio, uma lista de todos os menores existentes no districto que estiverem nas condições do artigo primeiro com declaração de seus nomes, idade, naturalidade, filiação, grãos de instrucção que possuírem, escolas que frequentam, e se são órphãos ou filhos de paes indigentes, e publical-a por editaes ou pela imprensa, por espaço de trinta dias a contar de 15 de Dezembro de cada anno, para que os paes, tutores ou patronos dos menores alistados cumpram o preceito do mesmo art. $1^{\circ}$.

$\int 2^{\circ}$ Propor à Camara para a approvação o plano da circumscripção territorial de que trata $\mathrm{o}$ art. 1 $^{\circ}$. (MONTE CARMELO, 1892).

A responsabilidade pela fiscalização da efetividade da instrução passa a ser atribuição de cada um dos membros do conselho, "afim de que não seja illudida a execução do pensamento capital da lei", devendo:

$\int 4^{\circ}$ Exigir dos paes, tutores ou patronos dos menores que frequentarem escola, os sujeitem a exame em dia, lugar e hora designados afim de se conhecer a qualidade e progresso da instruçcção que recebem.

$\int 5^{\circ}$ Julgar dos motivos, das faltas dos alumnos nas escolas quando não houver as mesmas por justificadas, admoestar os paes, tutores e patronos e impor-lhes a multa de 500 réis a $1 \$ 000$ réis por falta não justificada.

$\int 6^{\circ}$ Verificar o estado de pobreza dos menores e sua impossibilidade physica ou moral.

$\int 7^{\circ}$ Inspeccionar as escolas municipaes, e todas as outras que, por lei vigente ou ulterior fiquem sujeitas a fiscalisação do governo municipal.

$\int 8^{\circ}$ Designar aquelles de seus membros que devem presidir os exames annuaes n'essas escolas.

$\int 9^{\circ}$ Apresentar annualmente, até 7 de Janeiro circumstanciado relatório do estado de instrucção e aproveitamento nas escolas de seu districto, a Camara Municipal.

$\int 10$ Examinar o livro da matricula dos alunos a cargo do professor impondo a estes multa, de $10 \$ 000$ mil réis por vez, quando os mesmos livros não estiverem de conformidade com a lei.

$\int 11$ Promover em geral e por todos os meios legaes a seu alcance o aproveitamento e desenvolvimento da instrucção primaria. 
Antes da idade determinada no artigo $1^{\circ}$, os menores só poderiam abandonar a escola caso fossem julgados habilitados em exames ou se lhes sobreviessem impossibilidade física ou moral. As transferências para qualquer lugar do município deveriam ser comunicadas ao Conselho de Instrução ou a qualquer dos seus membros a respeito da nova residência do menor.

No capítulo III, reservado às penas e infracções, ficou estabelecido que, findo o prazo de trinta dias da publicação por edital, os pais que não mandassem à escola os menores sob sua guarda ou não lhes ministrassem a instrução primária por qualquer outro meio, incorreriam em multa de $20 \$ 000$, podendo ser elevada até $100 \$ 000$ no caso de persistir na infração. Também haveria imposição de pena caso o menor não estivesse na lista organizada pelo Conselho.

Nos termos do artigo $20^{\circ}$, os professores públicos ou subvencionados que se negassem a dar as informações exigidas pelos conselhos, incorreriam na pena de suspensão do exercício do magistério, na forma das leis em vigor e da liberdade do ensino no município, sendo que em caso de informações falsas, estavam sujeitos à perda da cadeira, podendo apresentar recurso necessário à câmara, dentro de três dias da imposição da pena, o qual poderia ser interposto tanto pelo professor quanto pelo Conselho.

Os órfãos e filhos de pais indigentes reconhecidos como tais a juízo do Conselho de Instrução receberiam do Conselho Distrital os objetos indispensáveis ao estudo: papel, tinta, pena, livros e pedras; os quais deveriam ser entregues pelos professores aos alunos, à proporção do necessário de cada um, correndo o fornecimento por conta da municipalidade. Para tanto, essas despesas seriam supridas pelo orçamento municipal, referente à verba, Instrução Pública, com uma rubrica de $900 \$ 000$ anuais para tal finalidade.

O capítulo I, do Título II da Lei, artigo $37^{\circ}$, estabeleceu a criação e manutenção de escolas a cargo da Câmara Municipal, na quantidade que fossem julgadas necessárias, nos distritos e bairros mais populosos do município, regidas por professores habilitados perante uma comissão examinadora nomeada pelo Presidente da Câmara. Os candidatos às cadeiras deveriam, no ato da inscrição, apresentar atestados comprovando sua idade, identidade e moralidade, sendo esta última realizada através de atestados de duas autoridades do lugar do último ano de residência do candidato.

Nos termos do artigo $40^{\circ}$, “[...] a idade legal para o magistério seria de 12 (doze) annos para os professores e 18 (dezoito) para as professoras, e a prova se fará por certidão de baptismo ou outro meio legal" (MONTE CARMELO, 1892). O ordenado dos professores foi fixado pelo Regulamento em $800 \$ 000$ para os professores da sede do distrito e povoações, e de $600 \$ 000$ para os professores dos bairros, e seria pago mensalmente, sem desconto, pelos 
cofres municipais, mediante atestado dos presidentes dos conselhos de instrução pública (CARMO DA BAGAGEM, 1895).

Dispôs o art. $43^{\circ}$ que: “[...] a frequencia d'estas escolas deverá ser no minimo de quinze alumnos e no maximo quarenta, sendo licito ao professor recusar a admissão de alumnos, além d'este numero". Ficou estabelecido que as aulas teriam início às 10 horas da manhã com término às " 2 horas da tarde" (CARMO DA BAGAGEM, 1895).

As matérias do ensino nas escolas seriam de primeira leitura e ortografia, aritmética até a teoria das frações decimais, proporções inclusive o sistema métrico, noções de gramática portuguesa, história do Brasil. Para o sexo feminino além destas matérias, o ensino compreendia trabalhos de agulha e economia doméstica.

Ao professor ficou vedado exercer outra ocupação estranha ao ensino. Recebeu poderes para aplicar aos alunos penas disciplinares, castigos morais e até mesmo expulsão das aulas, quando incorrigíveis, devendo neste caso comunicar o seu ato imediatamente ao Conselho de Instrução, acompanhado das justificativas.

Uma vez expulso, o aluno estava impedido de voltar à mesma escola. Por outro lado, os professores omissos no cumprimento dos seus deveres estariam sujeitos à multa aplicada pelo presidente do Conselho de Instrução, e só poderiam ser demitidos "[...] uma vez provados vicios de naturesa a impedilos de exercer o magisterio ou quando incurso em crime de naturesa infamante" (CARMO DA BAGAGEM, 1895, p. 33).

De acordo com o artigo $53^{\circ}$ do Regulamento, o ano letivo começaria no dia 06 de janeiro e terminaria no dia 07 de dezembro, sendo concedido ao professor o direito de até duas faltas por mês nas aulas, e sem desconto no ordenado, mediante justo motivo. Além das férias compreendidas durante o ano letivo, consideravam-se feriados os dias de festas nacionais e a Semana Santa.

Os exames escolares deveriam ser realizados no último dia do ano letivo, por meio de provas escritas e orais, das matérias exigidas no Regulamento, presididos por um dos membros do Conselho de Instrução e dois membros nomeados pelo Presidente, para composição a mesa.

Por força do art. $62^{\circ}$, ficou estabelecido que o ingresso para a docência seria por meio de concurso, a ser regulado pela Câmara Municipal, com afixação de editais para convocação dos candidatos às cadeiras com 30 dias de antecedência para a inscrição. O concurso deveria ser presidido pelo Presidente da Câmara, ou pelo seu substituto legal. As habilidades deveriam ser comprovadas mediante realização de provas escritas e orais, com duração máxima de 2 horas para sua realização. 
Ao final do ano letivo, caberia a um dos membros do Conselho de Instrução a aplicação dos exames escolares, mediante aplicação de provas escritas e orais das matérias previstas no Regulamento. Os professores que apresentassem 10 (dez) alunos adiantados nas matérias exigidas por este Regulamento teriam direito ao prêmio de $50 \$ 000$.

\section{Referências}

ALMEIDA, J. R. P. de. História da instrução pública no Brasil (1500-1889): história e legislação. Trad. Antonio Chizzotti. São Paulo: Educ., 1989.

ARAUJO, J. C. S. Grupos escolares em Minas Gerais: um estudo de caráter regional e demográfico sobre a Primeira República. Cadernos de História da Educação, Uberlândia, v. 11, nº 2, p. 349-477, jan./abr. 2012.

BORGES, G. F. de M.; ARAUJO, J. C. S. Regulamentação da instrução pública no município de Frutal, MG, Brasil, 1892. Cadernos de História da Educação, Uberlândia, MG, v. 14, n 1, p. 385-402, 2015. Disponível em: https://www.proquest.com/openview/07176bf3ac55ed88ebdaab87067353f2/ 1?pq-origsite $=$ gscholar\&cbl=2046359. Acesso em: 26 fev. 2019.

BRASIL. Lei de 15, de outubro de 1827. Manda criar escolas de primeiras letras em todas as cidades, vilas e lugares mais populares do Império.

Disponível em: http://www2.camara.leg.br/legin/fed/lei_sn/1824-1899/lei38398-15-outubro-1827-566692-publicacaooriginal-90222-pl.htm. Acesso em: 12 jun. 2018.

BRASIL. Lei de $\mathbf{1}^{\circ}$ de outubro de 1828 . Dá nova fórma ás Camaras Municipaes, marca suas attribuições, e o processo para a sua eleição, e dos Juizes de Paz. Disponível em:

https://www2.camara.leg.br/legin/fed/lei_sn/1824-1899/lei-38281-1outubro-1828-566368-publicacaooriginal-89945-pl.html. Acesso em: 04 dez. 2018.

BRASIL. Lei $\mathbf{n}^{\mathbf{0}} \mathbf{1 6}$, de 12 de agosto de 1834. Faz algumas alterações e addições á Constituição Politica do Imperio, nos termos da Lei de 12 de outubro de 1832. Disponível em:

http://www.planalto.gov.br/ccivil_03/leis/lim/LIM16.htm. Acesso em: 21 nov. 2018.

BRASIL. Decreto n ${ }^{\circ}$ 7, de 20 de novembro de 1889. Rio de Janeiro, 1989. https://www2.camara.leg.br/legin/fed/decret/1824-1899/decreto-7-20novembro-1889-517662-publicacaooriginal-1-pe.html. Acesso em 21/08/2021. 
BRASIL. Constituição da República dos Estados Unidos do Brasil de 1891. Disponível em:

http://www.planalto.gov.br/ccivil_03/constituicao/constituicao91.htm. Acesso em: 10 jun. 2018.

BRASIL. Lei $\mathbf{n}^{\circ}$ 2, de 14 de setembro de 1891. Contém a organização municipal. Disponível em: http:/ / mediaserver.almg.gov.br/upload/www/ $\mathrm{a}=\mathrm{d} \& \mathrm{i}=5434711224$. Acesso em: 26 jan. 2019.

CARMO DA BAGAGEM [MONTE CARMELO], CÂMARA MUNICIPAL. Lei ${ }^{\circ} 5$, de 06/11/1892. In: CARMO DA BAGAGEM [MONTE CARMELO], CÂMARA MUNICIPAL, Leis $\mathrm{n}^{\circ} 4$ de 5 de novembro de 1892 , $\mathrm{n}^{\circ} 5$ de 6 de novembro de $1892, \mathrm{n}^{\circ} 6$ de 7 de novembro de $1892, \mathrm{n}^{\circ} 7$ de 10 de novembro de $1892, \mathrm{n}^{\circ} 8$ de 11 de novembro de $1892, \mathrm{n}^{\circ} 9$ de 11 de novembro de 1892. Rio de Janeiro: Typographia Leuzinger, 1895, p. 25-37.

FERRARO, A. R. Analfabetismo no Brasil: tendência secular e avanços recentes. Resultados preliminares. Cadernos de Pesquisa, São Paulo, n. 52, p. 35-49, fev. 1985.

IBGE. ENCICLOPEDIA DOS MUNICÍPIOS BRASILEIROS. v. XXVI. Rio de Janeiro: Instituto Brasileiro de Geografia e Estatística, 1959. p. 129-134.

MATOS, A. V. de. Monte Carmelo: uma página das Gerais. Goiânia: Funape, 2013. p. 391.

MINAS GERAIS. Lei $\mathbf{n}^{\mathbf{0}} \mathbf{1 3}$, de 28 de março de 1835. Regula a criação das cadeiras de instrução primária, o provimento, e os ordenados dos professores. Disponível em:

https://www.almg.gov.br/consulte/legislacao/completa/completa.html? tipo $=$ LEI\&num $=13 \&$ comp $=\& a n o=1835$. Acesso em: 25 mar. 2019.

MINAS GERAIS. Lei $\mathbf{n}^{\circ} \mathbf{4 3 5}$, de 19 de outubro de 1848 , criando nesta capital um diretor geral da instrução pública, e um vice-diretor, e contendo outras disposições a respeito. Disponível em

https://www.almg.gov.br/consulte/legislacao/completa/completa.html? tipo $=L E I \&$ num $=435 \&$ comp $=\& a n o=1848$. Acesso em: 08 jun. 2021.

MINAS GERAIS. Constituição do Estado de Minas Gerais de 1891. Ouro Preto, MG: Assembleia Legislativa do Estado de Minas Gerais, 1891.

Disponíveliem: https://dspace.almg.gov.br/browse? type $=$ author\&value $=$ Minas + Gerais. $+\% 5 \mathrm{BConstitui} \% \mathrm{C} 3 \% \mathrm{~A} 7 \% \mathrm{C} 3 \% \mathrm{~A} 3 \mathrm{O}+$ \%281891\%29\%5D. Acesso em: 09 jun. 2018. 
MINAS GERAIS. Lei no 2, de 14 de agosto de 1891 . Contém a organização municipal. Ouro Preto, MG: Imprensa Official do Estado de Minas Gerais, 1895. Disponível em: https://mediaserver.almg.gov.br/upload/www/? $\mathrm{a}=\mathrm{d} \& \mathrm{i}=5434711224$. Acesso em: 26 fev. 2019.

MINAS GERAIS. Lei $\mathbf{n}^{\circ} \mathbf{1 1}$, de 13 de novembro de 1891. Disponível em: https://www.lexml.gov.br/urn/urn:lex:br;minas.gerais:estadual:lei:1891-1113;11. Acesso em: 07 jul. 2021.

MINAS GERAIS. Lei $\mathbf{n}^{\circ} \mathbf{2 3}$, de 24 de maio de 1892. Eleva à categoria de cidade todas as atuais vilas-sedes de comarca. Disponível em: https://www.almg.gov.br/consulte/legislacao/completa/completa.html? tipo $=$ LEI\&num $=23 \&$ comp $=\& a n o=1892$. Acesso em: 18 jan. 2019.

MINAS GERAIS. Lei $\mathbf{n}^{\circ}$ 41, de 03 de agosto de 1892. Dá nova organização à instrução pública do Estado de Minas. Ouro Preto, MG, 1892. Disponível em: https://www.almg.gov.br/consulte/legislacao/completa/completa-novamin.html?tipo $=$ LEI\&num $=41 \& \mathrm{comp}=\& a n o=1892 \&$ texto $={ }_{\text {original }}$. Acesso em: 19 jan. 2019.

MINAS GERAIS. Lei $\mathbf{n}^{\circ} \mathbf{2 8 6}$, de 25 de junho de 1900. Muda o nome da cidade, município e comarca do Carmo da Bagagem para cidade, município e comarca de Monte Carmelo. Disponível em:

https://www.almg.gov.br/consulte/legislacao/completa/completa.html? tipo $=$ LEI\&num $=286 \&$ comp $=\& a n o=1900$. Belo Horizonte, MG, 1900. Acesso em: 25 jan. 2019.

MINAS GERAIS. Lei 843, de 07 de setembro de 1923. Dispõe sobre a divisão administrativa do Estado. Disponível em:

https://www.almg.gov.br/consulte/legislacao/completa/completa-novamin.html?tipo $=$ Lei\&num $=843 \& a n o=1923$. Belo Horizonte, MG: 1923, s.p. Acesso em: 10 out. 2018.

MONTE CARMELO. Disponível em:

http://www.montecarmelo.mg.gov.br/perfil. Monte Carmelo, MG. Acesso em: 28 de out. de 2019, s.p.

MONTE CARMELO. CAPELA SÃO JOSÉ. Disponível em https://www.expressodocerrado.com.br/2017/03/20/capela-de-sao-jose/. Acesso em 07/07/2021.

MONTE CARMELO. Regulamento da instrução pública e particular. Monte Carmelo, MG: 1892. Mimeo. 
MOURÃO, P. K. C. O ensino em Minas Gerais no tempo do Império. Minas Gerais: Edição do Centro Regional de Pesquisas Educacionais da Faculdade de Direito da Universidade de Minas Gerais, 1959.

MOURÃO, P. K. C. O ensino em Minas Gerais no tempo da República. Minas Gerais: Edição do Centro Regional de Pesquisas Educacionais da Faculdade de Direito da Universidade de Minas Gerais, 1962.

NAGLE, J. Educação e sociedade na Primeira República. São Paulo: Rio de Janeiro, Fundação Nacional de Material Escolar, 1974.

PORTILHO, L. G. R. História e Histórias de Monte Carmelo. 1. ed. Monte Carmelo: Edição do Autor, 2013.

ROMANELLI, O. de O. História da Educação no Brasil. 29. ed. Petrópolis: Vozes, 2005.

SLYWITCH, Y. A história de Monte Carmelo contada por Yermak Slywitch. Monte Carmelo, MG: Apostila/Biblioteca Municipal de Monte Carmelo, Monte Carmelo, MG: 1995. 